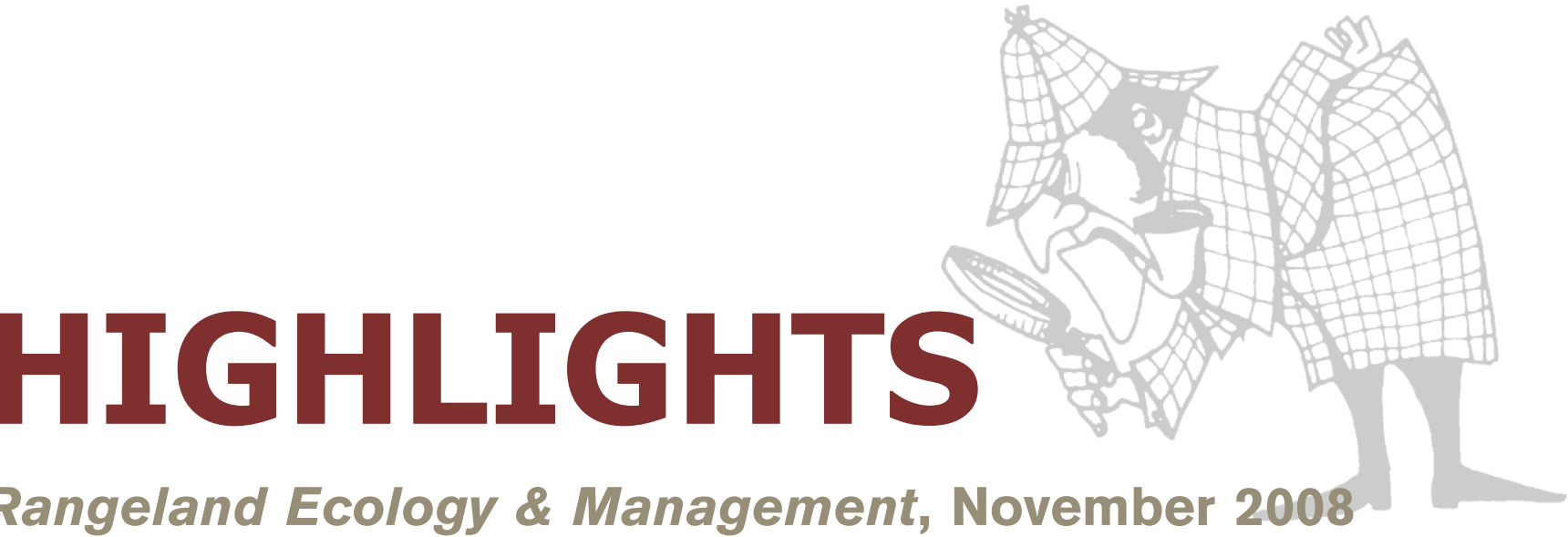

Fire History in a Chaparral Ecosystem: Implications for Conservation of a Native Ungulate

Vernon C. Bleich, Heather E. Johnson, Stephen A. Holl, Lora Konde, Steven G. Torres, and Paul R. Krausman

The natural fire cycle in chaparral ecosystems of southern California has been modified by fire suppression and, as a result, quality and distribution of habitat for mountain sheep (Ovis canadensis) has been affected. We modeled effects of fire history on winter ranges used by those specialized ungulates in the San Gabriel Mountains. There was a positive relationship between distributions of mountain sheep in otherwise suitable areas that had burned within $15 \mathrm{yr}$, but that relationship was negative in the absence of such fires. Use of prescribed fire to enhance availability and suitability of habitat for mountain sheep inhabiting chaparral should receive serious consideration by land managers.

\section{Plant Community and Soil Microbial Carbon and Nitrogen Responses to Fire and Clipping in a Southern Mixed Grassland}

W. N. Harris, T. W. Boutton, and R. J. Ansley

In a mixed grassland of the southern Great Plains, we tested the hypotheses that spring-season fire would increase the absolute biomass and relative proportion of $\mathrm{C}_{4}$ grasses in the plant community, decrease soil microbial biomass nitrogen $(\mathrm{N})$, and that clipping would reduce effects of fire. Contrary to our hypothesis, treatment effects were limited to $\mathrm{C}_{3}$ grasses and clipping was more important than fire in terms of effects on plant community composition. However, due to its greater capacity to reduce aboveground litter, fire had the greater impact on soil microbial carbon (C). This suggests that control of $\mathrm{N}$ cycling in this ecosystem is primarily microbial in nature, though dependent on inputs of plant $\mathrm{C}$ via litter.

\section{Mesquite, Tobosagrass, and Common Broomweed Responses to Fire Season and Intensity}

\section{R. J. Ansley, W. E. Pinchak, and D. L. Jones}

Our objective was to examine effects of fire seasonality and intensity on the woody legume honey mesquite (Prosopis glandulosa), the $\mathrm{C}_{4}$ midgrass tobosagrass (Pleuraphis mutica), and the annual forb common broomweed (Amphiachyris dracunculoides). Treatments included summer fires, high-intensity winter fires, low-intensity winter fires, and no-burn in replicated plots. Summer fire offered no clear advantage over high-intensity winter fire with respect to mesquite suppression. However, the increase in late-season tobosagrass percentage live tissue caused by summer fire may be advantageous for forage quality. In addition, patch burning summer fires to increase broomweed cover in selected areas may be useful for wildlife habitat.

\section{Postfire Recovery of Sagebrush Communities: Assessment Using SPOT-5 and Very Large-Scale Aerial Imagery}

Temuulen Tsagaan Sankey, Corey Moffet, and Keith Weber

We studied postfire recovery of sagebrush canopy cover using spectral mixture analysis with very large-scale aerial (VLSA) imagery and SPOT-5 imagery. Classification was successful and the SPOT-5 image estimates of percentage of shrub canopy cover were highly correlated with the estimates in the VLSA imagery $\left(R^{2}=0.82 ; P<0.0001\right)$. We determined that shrub cover recovered in approximately $27 \mathrm{yr}$ after fire with an average shrub cover of 38\%. Using similar analysis and image classification approach, postfire canopy changes in other sagebrush communities can be assessed. 


\section{Design and Analysis of Rangeland Experiments Along Continuous Gradients}

Nicola Koper, Darcy C. Henderson, John F. Wilmshurst, Patrick J. Fargey, and Robert A. Sissons

Treating grazing as a continuous rather than categorical variable may permit large-scale experiments to be conducted with fewer constraints on treatment replication to maintain statistical power. Using power analysis on a grazing experiment recently initiated in Grasslands National Park of Canada, we demonstrate that the continuous approach permits the use of fewer pastures, while maintaining the large pasture size required for realistic grazing behavior by cattle and improving our ability to answer biologically relevant questions regarding grazing effects on grassland ecosystems. We contend that this approach, when applied to grazing experiments, will help test hypotheses related to how grassland ecosystems respond to a gradient of disturbance regimes.

\section{Point Sampling to Stratify Biomass Variability in Sagebrush Steppe Vegetation \\ Patrick E. Clark, Stuart P. Hardegree, Corey A. Moffet, and Fredrick B. Pierson}

Traditional methods for sampling vegetation biomass are time-consuming and expensive and, because they are destructive, prevent repeated measures. We examined cost effectiveness of using a nondestructive point-sampling technique to stratify variability in subsequent biomass sampling on a sagebrush-bunchgrass rangeland site in southern Idaho. Double-sampling strategies in which half of the pointsampled plots were also measured for biomass yielded a cost savings of $39 \%$ with relatively minor reduction in biomass sample precision $(18 \% \pm 4 \mathrm{SD})$. Agricultural producers, natural resource managers, and researchers will greatly benefit from these findings through cost savings and increased availability of biomass information accruing when sampling cost constraints are reduced.

\section{Comparison of Medusahead-Invaded and Noninvaded Wyoming Big Sagebrush Steppe in Southeastern Oregon}

\section{Kirk W. Davies and Tony J. Svejcar}

Medusahead is an exotic annual grass invading sagebrush steppe rangelands in the western United States. To estimate the impact of medusahead invasion, vegetation characteristics were compared between invaded and noninvaded Wyoming big sagebrush steppe communities that had similar soils, topography, climate, and management. Noninvaded plant communities had greater cover, density, and biomass production of all native herbaceous functional groups compared to medusahead-invaded communities. Species richness and diversity were greater in the noninvaded than invaded plant communities. The results of this study suggest that medusahead invasion substantially alters vegetation characteristics of sagebrush steppe plant communities and, thereby, diminishes wildlife habitat, forage production, and ecosystem function.

\section{Native Plant Growth and Seedling Establishment in Soils Influenced by Bromus tectorum}

\section{Helen I. Rowe and Cynthia S. Brown}

It has been suggested that Bromus tectorum (cheatgrass) reduces arbuscular mycorrhizal fungi abundance and taxa diversity; if so, this may be one mechanism by which cheatgrass invades and dominates semiarid ecosystems. In a greenhouse, we grew cheatgrass and native plants in native soils and then planted native plants into these soils. In the field, we chemically treated cheatgrass, and then tested six seeding combinations. Cheatgrass influence on the soil community does not appear to contribute to its invasion success. Once cheatgrass is controlled on sites with sufficient native plant abundance, then native plant community reestablishment should be possible.

\section{Rough Agave Flowers as a Potential Feed Resource for Growing Goats}

\section{Miguel Mellado, Jose E. Garcia, and Wolfgang Pittroff}

For centuries, rough agave has been harvested to feed livestock in northern Mexico; however, the nutritional quality of this forage has not been completely described. Forty growing goats were offered air-dried rough agave flowers, which replaced alfalfa hay at $0 \%, 25 \%, 50 \%, 75 \%$, and $100 \%$ of the roughage portion of the diet. Results demonstrated the viability of using rough agave flowers in feedlot diets for goats, because replacing $75 \%$ alfalfa with this forage did not affect average daily gain or dry matter intake. It may be ecologically desirable to use this available forage instead of alfalfa in arid regions.

\section{Evaluating Livestock Grazing Use With Streambank Alteration Protocols: Challenges and Solutions}

\section{Jeremiah D. Heitke, Richard C. Henderson, Brett B. Roper, and Eric K. Archer}

We evaluated how streambank alteration was affected by protocol choice and personnel conducting these assessments. Protocols were generally repeatable among observers, but results were affected by factors not directly related to grazing intensity including 1) training, 2) professional background, 3) location and intensity of measurements, and 4) the protocol used. Experienced professionals recorded 
higher estimates of streambank alteration than did seasonal technicians. Different protocols resulted in different alteration estimates when estimating alteration at the same locations. Managers should therefore be careful when taking action based on a single evaluation, especially when near a management standard or threshold.

\section{Cattle Grazing Distribution and Efficacy of Strategic Mineral Mix Placement in Tropical Brazilian Pastures}

\section{Ricardo C. D. Goulart, Moacyr Corsi, Derek W.} Bailey, and Silvio S. Zocchi

Cattle grazing distribution can be a problem for rangeland managers in the tropical conditions of Brazil. A study was conducted in Brazil to evaluate factors affecting livestock distribution and to determine the efficacy of strategically placing mineral mix away from water to improve uniformity of grazing. Cattle avoided areas with taller grass and more forbs, and supplemental mineral mix location had little, if any, effect on livestock distribution. Strategic mineral placement away from water does not appear to be a persuasive and reliable tool to improve uniformity of cattle grazing patterns in tropical pastures that are 25 ha to 45 ha.

\section{Growth of Chickasaw Plum in Oklahoma}

Stacy W. Dunkin, Fred S. Guthery, and Rodney E. Will

Management of rangelands for wildlife and livestock entails understanding growth of clonal shrubs such as Chickasaw plum (Prunus angustifolia). We estimated age of stems and roots using growth rings and area of stands using a handheld global positioning system unit on rangelands in Oklahoma. Stands grew at similar rates among study sites with an estimate of $31.0 \mathrm{~m}^{2} \cdot \mathrm{yr}^{-1}$. Stem diameter increased more rapidly in north-central Oklahoma $\left(5.27 \mathrm{~mm} \cdot \mathrm{yr}^{-1}\right)$ than in northwestern Oklahoma $\left(3.68 \mathrm{~mm} \cdot \mathrm{yr}^{-1}\right)$. Knowledge of the area expansion rate of Chickasaw plum clones aids in management planning to increase or decrease canopy coverage by this shrub. 